\title{
The dominant role of animal social status in vertebrate seed dispersal
}

\author{
Savannah Bartel ${ }^{1}$ and John Orrock ${ }^{2}$ \\ ${ }^{1}$ University of Wisconsin Madison \\ ${ }^{2}$ University of Wisconsin
}

November 15, 2021

\begin{abstract}
Seed dispersal directly affects plant establishment, gene flow, and fitness. As a result, understanding patterns in seed dispersal is fundamental to understanding plant ecology and evolution, as well as addressing challenges of extinction and global change. Our ability to understand dispersal is limited because few frameworks have emerged that provide a means for predicting dispersal across time and space. We provide a novel framework that links seed dispersal to animal social status, a key component of behavior. Because social status affects individual resource access and movement, it provides a critical link to two factors that determine seed dispersal: the quantity of seeds dispersed and the spatial patterns of dispersal. Moreover, individual social status may have unappreciated effects on post-dispersal seed survival and recruitment when social status affects individual habitat use. Hence, environmental changes, such as selective harvesting and urbanization, that affect animal social structure may have unappreciated consequences for seed dispersal. The framework we present highlights these exciting new hypotheses linking environmental change, social structure, and seed dispersal. By outlining experimental approaches to test these hypotheses, we hope to facilitate studies across a wide diversity of plant-frugivore networks, which may uncover emerging hotspots or catastrophic losses of seed dispersal.
\end{abstract}

\section{Introduction}

Seed dispersal is a fundamental process for the survival, reproduction, and spread of plants because it is the only stage in the plant life cycle when many plants may use movement to colonize new habitats, escape competition, or evade attack by pathogens and herbivores (Howe \& Smallwood 1982; Howe \& Miriti 2000, 2004; Jordano 2000; Schupp et al. 2010; Hirsch et al. 2012; Carlo \& Tewksbury 2014). Animal-mediated seed dispersal is among the most common modes of seed dispersal (Howe \& Smallwood 1982; Jordano 2000; Herrera \& Pellmyr 2002); $64 \%$ of gymnosperm and $27 \%$ of angiosperm plant species rely on vertebrates for dispersal (Herrera 1989). As a result, understanding patterns in animal-mediated seed dispersal (zoochory) may provide a means to predict spatial patterns in plant recruitment (Beckman \& Rogers 2013), how plant species may respond to climate change (Dyer 1995; Cain et al. 2000; Kremer et al. 2012; Corlett \& Westcott 2013), and the outcomes of exotic plant invasions (Traveset \& Richardson 2014; Baltzinger et al. 2019). However, zoochory is notoriously variable in both the quantity of seeds dispersed and distance of seed movement (Schupp et al. 2010; Côrtes \& Uriarte 2013; Rogers et al. 2019). Consequently, developing predictive frameworks that enable more effective classification and prediction of zoochory has been an ongoing challenge to ecologists for several decades (Schupp et al. 2010; Côrtes \& Uriarte 2013; Zwolak 2018; Rogerset al. 2019; Zwolak \& Sih 2020).

While studies have shown that animal behavior provides a useful means for predicting spatial patterns in plant recruitment (Wang \& Smith 2002; Levey et al. 2005; Russo et al. 2006; Kremeret al. 2012; Beckman \& Rogers 2013; Sasal \& Morales 2013; Herrmann et al. 2016), relationships between specific dispersal agents and spatial patterns of dispersal often remain notably weak (Getzin et al. 2014; Schupp et al. 2017; but see Levey et al. 
2005 for an exception) due to high intraspecific variability in the behavior of seed-dispersal agents (Zwolak 2018). Such high intraspecific variation in disperser efficacy may have important pragmatic ramifications because species-level averages of disperser efficacy (i.e., mean number of seeds dispersed by individuals of one species) are often used to predict how changes in animal populations and communities may lead to losses in seed dispersal(e.g., Peres et al. 2016; Culot et al. 2017). For example, realized seed dispersal in fragmented habitats will be much lower than what is predicted by a species-average approach if individual animals that provide disproportionately greater contributions to seed dispersal are also the individuals most likely to be lost or exhibit changes in behavior in fragmented habitats (McConkey \& O'Farrill 2016; Zwolak 2018). As such, identifying traits of dispersal agents that explain intraspecific variation in behavior may provide the key to successfully predicting seed dispersal (Côrtes \& Uriarte 2013; González-Varo \& Traveset 2016; Schupp et al. 2017; Zwolak 2018; Brehm et al. 2019; Zwolak \& Sih 2020). Specifically, identifying individual traits that may affect the quantity of seeds handled, the distance that seeds are carried, and the microhabitat in which seeds are dispersed is critical to predicting variation in the effectiveness of individual agents of seed dispersal (Schupp et al. 2010; Brehm et al.2019).

Social status, which may reflect an individual's age, size, sex, or rank in a dominance hierarchy, may have an important bearing on individual behaviors that directly and indirectly affect seed dispersal by animals. The effectiveness of seed dispersal agents is described as the 'number of new adults produced by the dispersal activities of a disperser' (Schupp 1993). Seed dispersal effectiveness is the product of the quantity of seeds dispersed (quantitative component) and the probability of seedling establishment (quality component; Schupp et al. 2010). Since social status can affect individual diet composition, social status may predict intraspecific variation in the quantity of seeds dispersed (Fig. 1). Recent work by Tsuji et al. (2020) provides compelling evidence that social rank in Japanese macaques determines the quantity of seeds dispersed by an individual, and we suggest that this may be applicable for a broad diversity of taxa, including carnivores. We also highlight that social status affects individual space use, which may explain intraspecific variation in both the distance and quality of seed dispersal (Fig. 1). Much of the unresolved variation in seed dispersal could therefore be understood by a novel focus on animal social status.

We present a framework that provides important clarity on the relationships between individual social status, animal behavior, and seed dispersal, allowing for predictions of seed-dispersal patterns across a broad spectrum of systems. This framework may also be used to understand how animal social behavior affects our ability to mitigate several timely ecological challenges, such as biological invasions, plant persistence in urban environments, and plant persistence amidst climate change. We highlight that in many systems, subordinate individuals may be key agents of seed dispersal, illustrating that individuals with minimal demographic contributions may have substantial ecological contributions, i.e., subordinate animals may play a dominant role in seed dispersal. Hence, environmental changes that affect animal social structure may have unappreciated consequences for seed dispersal. This framework is informed by two perspectives, described below, and can be implemented across the wide diversity of plant-frugivore networks that include social frugivores, which may reveal emerging hotspots or catastrophic losses of seed dispersal in contexts where global change disrupts animal social structure. While our framework specifically focuses on zoochory, the general concepts and hypotheses that we present could be applied to other forms of animal-mediated dispersal (e.g., dispersal of fungi or parasites) that are mediated by individual diet and space use.

\section{Social status affects the quantity of seeds dispersed}

Social status is often predictably related to an individual's ability to monopolize preferred food items (Ward \& Webster 2016a), which likely generates intraspecific variation among dispersal agents in the quantity of seeds they disperse. This variation in seed dispersal may be most evident in systems where fruit is a supplementary food item that is less preferred to a food item that can be monopolized by dominant individuals, leading to greater quantity of seeds dispersed by subordinate individuals supplementing their diets with fruit. For example, coyotes (Canis latrans ) are social carnivores with highly variable diets that often include fruit (Parker 1995; Mastro 2011), and fruit consumption by coyotes can provide seed-dispersal services for a wide range of plant species across North America (Willson 1993; Cypher \& Cypher 1999; Roehm \& Moran 2013; 
Bartel \& Orrock 2021; Draper et al. 2021). Since coyote dominance hierarchies affect individual access to carrion (i.e., dominant individuals have greater access than subordinates; Gese et al. 1996; Atwood and Gese 2008), it is likely that subordinate individuals consume greater amounts of fruit (a secondary food item), transporting substantially greater quantities of seeds than dominant individuals (Fig. 1). Since transient (lessdominant) coyotes also have reduced access to ungulate carcasses than territorial (more-dominant) individuals (Gese 2001), it is likely that resident status is an important predictor of individual fruit consumption, and subsequent seed dispersal, in coyote populations. Moreover, social status related to space use is also likely to affect dispersal distance (see below).

It may be quite common that subordinate individuals disperse substantially more seeds than dominant individuals within carnivore populations (Box 1) as well as many primate populations where social status is known to dictate individual diet breadth. For example, in Kenya, higher-ranking female vervets (Cercopithecus aethiops ) consumed significantly less fruit than lower-ranking females (Isbellet al. 1999). This difference in diet is thought to be a result of higher-ranking females monopolizing fungi, a larger component of higher-ranking female diets, due to its abundance in restricted areas (Isbell et al. 1999). Rank differences in seed-dispersal efficacy may also be the opposite in primate populations where fruit is both preferred and can be monopolized by high-ranking individuals. In both blue monkeys (Cercopithecus mitis stuhlmanni) and chimpanzees (Pan troglodytes ), high-ranking individuals consume significantly more fruit than low-ranking individuals, which consume significantly more foliage (Pazol \& Cords 2005; Murray et al.2006). Predicting how dominant and subordinate individuals vary in effectiveness as seed-dispersal agents therefore requires an understanding of which food item (fruit or an alternative resource) is both preferred and monopolizable by dominant individuals (Fig. 1).

\section{The distance and quality of seed dispersal may vary with social status}

Social status predictably impacts individual space use such that social status may be used to predict the distance and quality of seed dispersal, specifically characteristics of deposition sites which affect the probability of post-dispersal predation and seedling establishment (e.g., suitable microsite availability and abundance of natural enemies: Schupp 1993; Schupp et al. 2010). In systems where a resource can be monopolized (e.g., fruiting trees), the defense of resources by dominant individuals can create situations where subordinates steal defended resources and then move far away to avoid antagonistic encounters, thereby elongating seed-dispersal kernels (Box 2, Fig. 2A). The contrast in space use between resource-defending dominant individuals and resource-stealing subordinates has been explicitly linked to patterns in seed dispersal in a study of flying foxes (McConkey \& Drake 2006). However, thieving behaviors by subordinates have been documented in a variety of taxa, including birds, primates, and bats (Sallabanks 1993; McConkey \& Drake 2006; Ward \& Webster 2016b; Tsuji et al.2020), indicating that this is a potentially profitable, yet largely untapped area of research that may elucidate patterns in seed-dispersal kernels.

For group-living large mammals, an individual's rank within a dominance hierarchy has well-documented effects on its movement across landscapes. Dominant individuals often have more restricted home ranges, spending more time in predictable, preferred habitat types (Aycrigg \& Porter 1997; Henry et al. 2005; Wittemyer et al. 2007; Dorning \& Harris 2017; Kamler et al. 2019). Subordinate individuals often forego foraging efficiency to mitigate competition with dominants (Henryet al. 2005; Gilbert-Norton et al. 2013; Dorning \& Harris 2017), and this increased movement likely leads to an increase in the diversity of habitats in which seeds may be deposited as well as increased dispersal distance (Fig. 1). Broader distinctions between territorial and transient individuals may also be used to predict spatial patterns in seed dispersal and recruitment. For example, territorial males in lekking blackbuck antelope (Antilope cervicapra) populations defecate in dung piles, leading to spatially concentrated patterns of seed arrival within male territories and substantially higher rates of seedling recruitment on territories than on random sites (Jadeja et al. 2013). Since non-territorial males in mixed-sex herds range over large areas and do not predictably deposit seeds in dung piles, seed dispersal by non-territorial individuals is likely lower in quality. This example highlights that commonly used methods for estimating seed dispersal that rely upon individual movement patterns and gut-retention time may not accurately capture intraspecific variation in dispersal efficacy if the quality 
of deposition site for plant recruitment is not also evaluated. Since individual movement and habitat use is affected by social status, the quality of seed-deposition sites may vary among individuals of different social statuses (Fig. 1). Studies that not only estimate seed dispersal but also measure post-dispersal seed fate (i.e., seed predation and recruitment) at deposition sites will provide greater clarity on how the quality of seed dispersal varies between individuals of different social statuses. For example, past work shows that seed deposition in coyote scat increases seed survival for rodent-preferred seeds but decreases seed survival for arthropod-preferred seeds due to the contrasting effects of mesopredator scat on rodents (aversion) and arthropods (attraction; Bartel and Orrock 2021). Hence, if dominant individuals deposit seeds in microhabitats with different granivore communities than the microhabitats in which subordinates deposit seeds, then the probability of post-dispersal seed survival may drastically differ. This contrast may be most evident in group-living canids, like coyotes, where dominant individuals spend more time maintaining territory boundaries, often through scent-marking and scat deposition, than subordinate individuals (Gese 2001). Since territory boundaries often fall along habitat edges, including roads and trails, seed fate may differ among dominant- and subordinate-dispersed seeds if granivores either avoid or prefer edges.

An individual's efficacy as a seed-dispersal agent may change over its lifetime if social status changes over a lifetime. For example, social dominance in grizzly bear (Ursus arctos horribilis ) populations is typically a result of individual size (larger bears are dominant over smaller bears) and reproductive status (females with cubs are subordinate to single males; Ben-David et al. 2004; Gende and Quinn 2004). Since individual social status affects bear diet and space use (Box 1), juvenile males are likely to become less effective seed-dispersal agents over their lifetime, and females are likely to be most effective seed-dispersal agents during their lifetime when they are rearing cubs. The capacity for an individual's efficacy as a seed-dispersal agent to rapidly change raises a clear distinction between the effects of social status and personality on seed dispersal. While definitions of animal personalities are often context- or system-specific, personality is most broadly defined as individual differences in behavior that are consistent across time and/or contexts (Dall et al. 2004; Stamps \& Groothuis 2010). In contrast, an individual's social status has the capacity to change across time or context, particularly as a result of changes in the individual's social environment. While individual personality traits can sometimes be correlated with social dominance (Briffa et al. 2015), personality and social dominance are not related in many animal societies (Favati et al. 2013; Funghi et al. 2015; Devostet al. 2016). Dominance is the product of myriad environmental factors (e.g., relative size, relative age, reproductive status, maternal rank, social alliances; Favati et al. 2013; Funghi et al. 2015; Devost et al. 2016; Strauss and Holekamp 2019; Ilany et al. 2021), but personality is by definition consistent across time and context, though it may develop in response to individual experience (Stamps \& Groothuis 2010). Hence, individual behaviors that are a result of personality should remain consistent over short timespans, but any changes to an individual's social environment that lead to a rapid change in social status are expected to rapidly change individual behavior and efficacy as a seed-dispersal agent.

\section{Consequences of global change for socially-mediated seed dispersal}

Our framework illustrates that in many systems where fruit is a supplemental resource for animals (e.g., carnivores and folivores), subordinate individuals are likely to be the most effective seed-dispersal agents, and thus may be critical for understanding patterns in plant populations in the Anthropocene. First, since subordinate individuals have less restricted home ranges and are more likely to disperse beyond current conspecific territories (Aycrigg \& Porter 1997; Henry et al. 2005; Dorning \& Harris 2017; Kamler et al. 2019), subordinate individuals may be more likely to provide long-distance seed-dispersal events. Long-distance seed dispersal is critical for plant species range expansion to track changing climates (Dyer 1995; Cain et al. 2000; Corlett \& Westcott 2013). Hence, subordinate individuals may facilitate range expansions that allow plant species track changing climates (Fig. 3A). Second, since subordinate individuals are more likely to utilize less-preferred habitats (Aycrigg \& Porter 1997; Wittemyer et al.2007; Ward et al. 2018), and urban habitats are often demographic sinks (Vierling 2000; Lamb et al. 2017, 2020), subordinate individuals may be more likely to transport seeds into urban habitats, playing a potentially unappreciated role in promoting the spread and persistence of some plant populations in urban landscapes (Fig. 3B). Differences in movement across fragmented landscapes due to social status may also have important, yet unappreciated implications for the 
efficacy of conservation corridors (i.e., thin strips of habitat connecting otherwise isolated patches). While corridors have been shown to increase plant species diversity, including animal-dispersed plants (Damschen et al. 2006, 2019), there is limited knowledge of how an animal's social status affects its propensity to move through corridors (but see Box 1 for discussion of work by Ford et al. (2017)). Since subordinate individuals typically forage in a larger number of patches in a landscape and are more likely to disperse from natal habitats, we predict that subordinate individuals may disproportionately contribute to seed movement through corridors and the consequent benefits of corridors to plant diversity (Fig. 3C). Initiatives to restore plant communities through corridor implementation may therefore require wildlife management that maintains or restores social structure in animal populations. Finally, if subordinate individuals have significant contributions to the quantity and spatial spread of seed dispersal, then subordinate individuals may facilitate the spread of invasive plants.

Our framework also highlights how environmental changes that modify animal social structure and behavior may have indirect consequences for plant populations through changes in seed dispersal effectiveness. For example, rank-dependent differences in diet and space use often only occur during seasons when the preferred resource is limited and can be monopolized (Pazol \& Cords 2005; Wittemyer et al. 2007; Tsujiet al. 2020). Events that cause an overabundance of a preferred resource (e.g., masting or human subsidies) could therefore lead to a cryptic function loss of seed dispersal by subordinates (McConkey and O'Farrill 2015; Box 2). It has been shown that animal social network structure is relaxed near anthropogenic habitats (Belton et al.2018; Morrow et al. 2019), indicating that areas of high human activity may be hotspots of cryptic function loss of seed dispersal if high-quality foods are no longer monopolized by dominant individuals. While it is appreciated that animal species extinction can lead to catastrophic loss in plant biomass due to seed-dispersal limitation (Peres et al. 2016), we posit that shifts in animal social behavior may have similar deleterious effects on plant biomass. A study by McConkey and Drake (2006) on seed dispersal by flying foxes illustrated that seed dispersal services may be lost when animal population densities fall below a threshold for densitydependent behaviors that lead to seed dispersal (Box 2). Consequently, the functional role of animals as seed-dispersal agents can be lost in the early stages of species decline when social behaviors diminish, long before species become rare (McConkey \& Drake 2006; McConkey \& O'Farrill 2015, 2016). Finally, while it is known that harvesting frugivorous animals causes seed-dispersal limitation (Peres et al. 2016), we posit that selective harvesting of dominant individuals may also lead to seed-dispersal limitation (Box 1). By removing dominant males or matriarchs from populations, selective harvesting can disrupt social systems (Milner et al. 2007), which may lead to reductions in seed-dispersal efficacy by subordinate individuals if dominant individuals are no longer able to establish territories or defend preferred resources.

It is unclear if changes in the plant communities and the distribution of resources may indirectly affect seed dispersal by changing the identity and monopolizability of resources for social animals. For example, human disturbances may modify the types of resources available, which may alter consumer resource preferences (e.g., dominant individuals that used to monopolize fungus patches switch to consuming agricultural crops) and the quantity of seeds dispersed by individuals. Encounter rates with resources should also change the nature of resource preferences as well as the economics of resource defense. Global-change forces, such as introduced plant invasions, that reduce encounter rates with preferred resources may change the realization of preference as well as the opportunities to monopolize preferred resources. Moreover, it is possible that in cases where consumer preference does not change, the monopolizability of preferred resources is diminished, which may change the quantity of seeds dispersed by subordinate individuals. For example, recent work suggests that carnivores may abandon carcasses more quickly in the presence of human activity (Suraci et al. 2019), indicating that spatially clumped resources may be less defended by dominant individuals when located near human activity, possibly leading to greater access to preferred resources for subordinate individuals.

\section{Future Directions}

While centuries of research have been devoted to characterizing and understanding animal social behavior, there is a surprisingly limited amount of knowledge of how social behaviors affect trophic interactions to 
generate patterns in communities. Since animal social status has predictable, well-documented effects on individual diet and movement, investigating how animal social behaviors contribute to intraspecific variation in seed dispersal effectiveness may explain much of the unresolved variation in seed dispersal and plant recruitment. There is an important lacuna in non-primate systems for understanding how social status may explain intraspecific variation in diet and space use, and consequently seed dispersal effectiveness. While a few studies show that social status explains individual diet composition in some potential seed-dispersing vertebrates (e.g., pampas foxes and pronghorn; Dennehy 2001; Castillo et al. 2011), there is limited knowledge of how it may explain the well-documented dietary variation in omnivorous species where social status is known to determine resource access, such as many carnivore species (Box 1). Since this current lacuna is likely due to the difficulty of tracking both seed fate and the behaviors of cryptic animals, we suggest methods for systems where animal behavior and seed fate cannot be measured by direct human observation of wild animals (Table 1).

Our framework also highlights that individual social status may play an unappreciated role in determining post-dispersal seed survival and recruitment when individuals of different social statuses utilize different habitat types. We therefore strongly suggest that future research measuring individual behavior, social status, and seed movement also evaluate the quality of seed-deposition sites by measuring rates of postdispersal seed predation and seedling establishment (Table 1). We predict that this framework will be most important in systems where plant species are dispersal limited, animal social status affects individual diet and movement, and fleshy fruit is an essential dietary supplement for subordinate individuals (e.g., carnivore and folivore populations). Understanding how social status affects seed dispersal may be most critical in systems where animal social structure is modified or destabilized, illuminating cryptic hotspots of seed dispersal loss.

\section{Acknowledgements}

We thank K.B. Strier, J. Kraus, C. Zirbel, C. Keller, M. Fuka, and A. Weidemann for thoughtful discussion and helpful comments on the manuscript. This work was supported by NSF DEB 2042211.

\section{References}

Araújo, M.S., Bolnick, D.I. \& Layman, C.A. (2011). The ecological causes of individual specialisation. Ecol. Lett. , 14, 948-958.

Atwood, T.C. \& Gese, E.M. (2008). Coyotes and recolonizing wolves: Social rank mediates risk-conditional behaviour at ungulate carcasses. Anim. Behav. , 75, 753-762.

Aycrigg, J.L. \& Porter, W.F. (1997). Sociospatial dynamics of white-tailed deer in the Central Adirondack Mountains, New York.J. Mammal. , 78, 468-482.

Baltzinger, C., Karimi, S. \& Shukla, U. (2019). Plants on the move: Hitch-hiking with ungulates distributes diaspores across landscapes. Front. Ecol. Evol., 7.

Bartel, S.L. \& Orrock, J.L. (2021). An omnivorous mesopredator modifies predation of omnivore-dispersed seeds. Ecosphere, 12, e03369.

Bartoń, K.A., Zwijacz-Kozica, T., Zięba, F., Sergiel, A. \& Selva, N. (2019). Bears without borders: Longdistance movement in human-dominated landscapes. Glob. Ecol. Conserv. , 17, 1-8.

Beckman, N.G. \& Rogers, H.S. (2013). Consequences of seed dispersal for plant recruitment in tropical forests: Interactions within the seedscape. Biotropica , 45, 666-681.

Belton, L.E., Cameron, E.Z. \& Dalerum, F. (2018). Social networks of spotted hyaenas in areas of contrasting human activity and infrastructure. Anim. Behav. , 135, 13-23.

Ben-David, M., Titus, K. \& Beier, L.V.R. (2004). Consumption of salmon by Alaskan brown bears: A trade-off between nutritional requirements and the risk of infanticide? Oecologia , 138, 465-474. 
Brehm, A.M., Mortelliti, A., Maynard, G.A. \& Zydlewski, J. (2019). Land-use change and the ecological consequences of personality in small mammals. Ecol. Lett. , 22, 1387-1395.

Briffa, M., Sneddon, L.U. \& Wilson, A.J. (2015). Animal personality as a cause and consequence of contest behaviour. Biol. Lett. , 11, 20141007.

Cain, M.L., Milligan, B.G. \& Strand, A.E. (2000). Long-distance seed dispersal in plant populations. Am. J. Bot. , 87, 1217-1227.

Carlo, T.A. \& Tewksbury, J.J. (2014). Directness and tempo of avian seed dispersal increases emergence of wild chiltepins in desert grasslands. J. Ecol. , 102, 248-255.

Castillo, D.F., Birochio, D.E., Lucherini, M. \& Casanave, E.B. (2011). Diet of adults and cubs of Lycalopex gymnocercus in pampas grassland: A validation of the optimal foraging theory? Ann. Zool. Fennici, 48, $251-256$.

Clevenger, A.P. \& Waltho, N. (2005). Performance indices to identify attributes of highway crossing structures facilitating movement of large mammals. Biol. Conserv. , 121, 453-464.

Corlett, R.T. \& Westcott, D.A. (2013). Will plant movements keep up with climate change? Trends Ecol. Evol. , 28, 482-488.

Côrtes, M.C. \& Uriarte, M. (2013). Integrating frugivory and animal movement: a review of the evidence and implications for scaling seed dispersal. Biol. Rev. , 88, 255-272.

Creel, S. (2001). Social dominance and stress hormones. Trends Ecol. Evol. , 16.

Culot, L., Bello, C., Batista, J.L.F., do Couto, H.T.Z. \& Galetti, M. (2017). Synergistic effects of seed disperser and predator loss on recruitment success and long-term consequences for carbon stocks in tropical rainforests. Sci. Rep., 7, 7662 .

Cypher, B.L. \& Cypher, E.A. (1999). Germination rates of tree seeds ingested by coyotes and raccoons. Am. Midl. Nat. , 142, 71-76.

Cypher, B.L., Madrid, A.Y., Van Horn Job, C.L., Kelly, E.C., Harrison, S.W.R. \& Westall, T.L. (2014). Multi-population comparison of resource exploitation by island foxes: Implications for conservation. Glob. Ecol. Conserv. , 2, 255-266.

Dall, S.R.X., Houston, A.I. \& McNamara, J.M. (2004). The behavioural ecology of personality: consistent individual differences from an adaptive perspective. Ecol. Lett. , 7, 734-739.

Damschen, E.I., Brudvig, L.A., Burt, M.A., Fletcher, R.J., Haddad, N.M., Levey, D.J., et al. (2019). Ongoing accumulation of plant diversity through habitat connectivity in an 18-year experiment.Science (80-. ). , 365, $1478-1480$.

Damschen, E.I., Haddad, N.M., Orrock, J.L., Tewksbury, J.J. \& Levey, D.J. (2006). Corridors increase plant species richness at large scales.Science (80-. ). , 313, 1284-1286.

Darimont, C.T., Paquet, P.C. \& Reimchen, T.E. (2009). Landscape heterogeneity and marine subsidy generate extensive intrapopulation niche diversity in a large terrestrial vertebrate. J. Anim. Ecol. , 78, 126-133.

Davis, N.E., Forsyth, D.M., Triggs, B., Pascoe, C., Benshemesh, J., Robley, A., et al. (2015). Interspecific and geographic variation in the diets of sympatric carnivores: dingoes/wild dogs and red foxes in south-eastern Australia. PLoS One, 10, e0120975.

Deacy, W.W., Erlenbach, J.A., Leacock, W.B., Stanford, J.A., Robbins, C.T. \& Armstrong, J.B. (2018). Phenological tracking associated with increased salmon consumption by brown bears. Sci. Rep. , 8, 1-9.

Dennehy, J.J. (2001). Influence of social dominance rank on diet quality of pronghorn females. Behav. Ecol. , 12, 177-181. 
Devost, I., Jones, T.B., Cauchoix, M., Montreuil-Spencer, C. \& Morand-Ferron, J. (2016). Personality does not predict social dominance in wild groups of black-capped chickadees. Anim. Behav. , 122, 67-76.

Do, E., San, L., Somers, M.J. \& Walters, M. (2009). Autumn diet of black-back jackals (Canis mesomelas ) in the thicket biome of South Africa. Wildl. Biol. Pract.

Dorning, J. \& Harris, S. (2017). Dominance, gender, and season influence food patch use in a group-living, solitary foraging canid.Behav. Ecol. , 28, 1302-1313.

Draper, J.P., Atwood, T.B., Beckman, N.G., Kettenring, K.M. \& Young, J.K. (2021). Mesopredator frugivory has no effect on seed viability and emergence under experimental conditions. Ecosphere, 12.

Dumond, M., Villard, M.-A. \& Tremblay, É. (2001). Does coyote diet vary seasonally between a protected and an unprotected forest landscape?Ecoscience , 8, 301-310.

Dyer, J.M. (1995). Assessment of climatic warming using a model of forest species migration. Ecol. Modell. , 79, 199-219.

Favati, A., Leimar, O., Radesa"ter, T. \& Løvlie, H. (2013). Social status and personality: stability in social state can promote consistency of behavioural responses. Proc. R. Soc. B , 281, 20132531.

Ford, A.T., Barrueto, M. \& Clevenger, A.P. (2017). Road mitigation is a demographic filter for grizzly bears. Wildl. Soc. Bull. , 41, 712-719.

Funghi, C., Leitão, A. V., Ferreira, A.C., Mota, P.G. \& Cardoso, G.C. (2015). Social dominance in a gregarious bird is related to body size but not to standard personality assays. Ethology , 121, 84-93.

García-Rodríguez, A., Albrecht, J., Szczutkowska, S., Valido, A., Farwig, N. \& Selva, N. (2021). The role of the brown bear Ursus arctos as a legitimate megafaunal seed disperser. Sci. Rep., 11, 1-11.

Gende, S.M. \& Quinn, T.P. (2004). The relative importance of prey density and social dominance in determining energy intake by bears feeding on Pacific salmon. Can. J. Zool. , 82, 75-85.

Gese, E.M. (2001). Territorial defense by coyotes (Canis latrans ) in Yellowstone National Park, Wyoming: who, how, where, when, and why. Can. J. Zool. , 79, 980-987.

Gese, E.M., Ruff, R.L. \& Crabtree, R.L. (1996). Foraging ecology of coyotes (Canis latrans ): the influence of extrinsic factors and a dominance hierarchy. Can. J. Zool. , 74, 769-783.

Getzin, S., Wiegand, T. \& Hubbell, S.P. (2014). Stochastically driven adult-recruit associations of tree species on Barro Colorado Island.Proc. R. Soc. B , 281, 10140922.

Gilbert-Norton, L.B., Wilson, R.R. \& Shivik, J.A. (2013). The effect of social hierarchy on captive coyote (Canis latrans) foraging behavior. Ethology, 119, 335-343.

González-Varo, J.P. \& Traveset, A. (2016). The labile limits of forbidden interactions. Trends Ecol. Evol. , 31.

Gosselin, J., Leclerc, M., Zedrosser, A., Steyaert, S.M.J.G., Swenson, J.E. \& Pelletier, F. (2017). Hunting promotes sexual conflict in brown bears. J. Anim. Ecol. , 86, 35-42.

Hämäläinen, A., Broadley, K., Droghini, A., Haines, J.A., Lamb, C.T., Boutin, S., et al. (2017). The ecological significance of secondary seed dispersal by carnivores. Ecosphere, 8, e01685.

Henry, C., Poulle, M.-L. \& Roeder, J.-J. (2005). Effect of sex and female reproductive status on seasonal home range size and stability in rural red foxes (Vulpes vulpes ). Écoscience, 12, 202-209.

Herrera, C.M. (1989). Frugivory and seed dispersal by carnivorous mammals, and associated fruit characteristics, in undisturbed Mediterranean habitats. Oikos , 55, 250-252. 
Herrera, C.M. \& Pellmyr, O. (2002). Plant-Animal Interactions: An Evolutionary Approach . WileyBlackwell, Hoboken, NJ.

Herrmann, J.D., Carlo, T.A., Brudvig, L.A., Damschen, E.I., Haddad, N.M., Levey, D.J., et al. (2016). Connectivity from a different perspective: Comparing seed dispersal kernels in connected vs. unfragmented landscapes. Ecology, 97, 1274-1282.

Hirsch, B.T., Kays, R., Pereira, V.E. \& Jansen, P.A. (2012). Directed seed dispersal towards areas with low conspecific tree density by a scatter-hoarding rodent. Ecol. Lett. , 15, 1423-1429.

Howe, H.F. \& Miriti, M.N. (2000). No question: Seed dispersal matters. Trends Ecol. Evol. , 15, 434-436.

Howe, H.F. \& Miriti, M.N. (2004). When seed dispersal matters.Bioscience , 54, 651-660.

Howe, H.F. \& Smallwood, J. (1982). Ecology of seed dispersal.Annu. Rev. Ecol. Syst., 13, 201-228.

Ilany, A., Holekamp, K.E. \& Akçay, E. (2021). Rank-dependent social inheritance determines social network structure in spotted hyenas.Science (80-. ). , 373, 348-352.

Isbell, L.A., Pruetz, J.D., Lewis, M. \& Young, T.P. (1999). Rank differences in ecological behavior: A comparative study of patas monkeys (Erythrocebus patas) and vervets (Cercopithecus aethiops).Int. J. Primatol. , 20, 257-272.

Jadeja, S., Prasad, S., Quader, S. \& Isvaran, K. (2013). Antelope mating strategies facilitate invasion of grasslands by a woody weed.Oikos , 122, 1441-1452.

Jordano, P. (2000). Fruits and frugivory. In: Seeds: The ecology of regeneration in plant communities (ed. Fenner, M.). CAB International, Wallingford, UK.

Kamler, J.F., Klare, U. \& Macdonald, D.W. (2020). Seed dispersal potential of jackals and foxes in semi-arid habitats of South Africa.J. Arid Environ., 183, 104284.

Kamler, J.F., Stenkewitz, U., Gharajehdaghipour, T. \& Macdonald, D.W. (2019). Social organization, home ranges, and extraterritorial forays of black-backed jackals. J. Wildl. Manage., 83, 1800-1808.

Kremer, A., Ronce, O., Robledo-Arnuncio, J.J., Guillaume, F., Bohrer, G., Nathan, R., et al. (2012). Longdistance gene flow and adaptation of forest trees to rapid climate change. Ecol. Lett. , 15, 378-392.

Lamb, C.T., Ford, A.T., Mclellan, B.N., Proctor, M.F., Mowat, G., Ciarniello, L., et al. (2020). The ecology of human-carnivore coexistence. Proc. Natl. Acad. Sci. , 117, 17876-17883.

Lamb, C.T., Mowat, G., McLellan, B.N., Nielsen, S.E. \& Boutin, S. (2017). Forbidden fruit: human settlement and abundant fruit create an ecological trap for an apex omnivore. J. Anim. Ecol. , 86, 55-65.

Leclerc, M., Zedrosser, A., Swenson, J.E. \& Pelletier, F. (2019). Hunters select for behavioral traits in a large carnivore. Sci. Rep. , 9, 1-8.

Levey, D.J., Bolker, B.M., Tewksbury, J.J., Sargent, S. \& Haddad, N.M. (2005). Effects of landscape corridors on seed dispersal by birds.Science (80-. ). , 309.

López-Bao, J. V. \& González-Varo, J.P. (2011). Frugivory and spatial patterns of seed deposition by carnivorous mammals in anthropogenic landscapes: a multi-scale approach. PLoS One, 6, e14569.

López-Bao, J. V., González-Varo, J.P. \& Guitián, J. (2015). Mutualistic relationships under landscape change: carnivorous mammals and plants after 30 years of land abandonment. Basic Appl. Ecol. , 16, 152-161.

Manlick, P.J., Petersen, S.M., Moriarty, K.M. \& Pauli, J.N. (2019). Stable isotopes reveal limited Eltonian niche conservatism across carnivore populations. Funct. Ecol., 33, 335-345.

Mastro, L.L. (2011). Life history and ecology of coyotes in the Mid-Atlantic states: a summary of the scientific literature.Southeast. Nat. , 10, 721-730. 
McConkey, K.R. \& Drake, D.R. (2006). Flying foxes cease to function as seed dispersers long before they become rare. Ecology , 87, 271-276.

McConkey, K.R. \& O'Farrill, G. (2015). Cryptic function loss in animal populations. Trends Ecol. Evol. , 30.

McConkey, K.R. \& O'Farrill, G. (2016). Loss of seed dispersal before the loss of seed dispersers. Biol. Conserv. , 201, 38-49.

Milner, J.M., Nilsen, E.B. \& Andreassen, H.P. (2007). Demographic side effects of selective hunting in ungulates and carnivores. Conserv. Biol. , 21, 36-47.

Morrow, K.S., Glanz, H., Ngakan, P.O. \& Riley, E.P. (2019). Interactions with humans are jointly influenced by life history stage and social network factors and reduce group cohesion in moor macaques (Macaca maura ). Sci. Rep. , 9, 20162.

Murray, C.M., Eberly, L.E. \& Pusey, A.E. (2006). Foraging strategies as a function of season and rank among wild female chimpanzees (Pan troglodytes ). Behav. Ecol. , 1020-1028.

Newsome, S.D., Garbe, H.M., Wilson, E.C. \& Gehrt, S.D. (2015). Individual variation in anthropogenic resource use in an urban carnivore. Oecologia , 178, 115-128.

Parker, G. (1995). Eastern Coyote: The Story of Its Success . 1st edn. Nimbus Publishing, Halifax, Nova Scotia.

Pazol, K. \& Cords, M. (2005). Seasonal variation in feeding behavior, competition and female social relationships in a forest dwelling guenon, the Blue Monkey (Cercopithecus mitis stuhlmanni), in the Kakamega Forest, Kenya. Behav. Ecol. Sociobiol., 58, 566-577.

Peres, C.A., Emilio, T., Schietti, J., Desmoulière, S.J.M. \& Levi, T. (2016). Dispersal limitation induces long-term biomass collapse in overhunted Amazonian forests. Proc. Natl. Acad. Sci. U. S. A. , 113, 892-897.

Roehm, K. \& Moran, M.D. (2013). Is the coyote (Canis latrans) a potential seed disperser for the American Persimmon (Diospyros virginiana)? Am. Midl. Nat. , 169, 416-421.

Rogers, H.S., Beckman, N.G., Hartig, F., Johnson, J.S., Pufal, G., Shea, K., et al. (2019). The total dispersal kernel: A review and future directions. AoB Plants , 11, 1-13.

Rost, J., Pons, P. \& Bas, J.M. (2012). Seed dispersal by carnivorous mammals into burnt forests: An opportunity for non-indigenous and cultivated plant species. Basic Appl. Ecol. , 13, 623-630.

Russo, S.E., Portnoy, S. \& Augspurger, C.K. (2006). Incorporating animal behavior into seed dispersal models: Implications for seed shadows. Ecology , 87, 3160-3174.

Sallabanks, R. (1993). Fruit defenders vs. fruit thieves: Winter foraging behavior in American robins. J. F. Ornithol. , 64, 42-48.

Sasal, Y. \& Morales, J.M. (2013). Linking frugivore behavior to plant population dynamics. Oikos , 122, 95-103.

Schupp, E.W. (1993). Quantity, quality and the effectiveness of seed dispersal by animals. Vegetatio, 107/108, $15-29$.

Schupp, E.W., Jordano, P. \& Gómez, J.M. (2010). Seed dispersal effectiveness revisited: A conceptual review. New Phytol. , 188, 333-353.

Schupp, E.W., Jordano, P. \& Gómez, J.M. (2017). A general framework for effectiveness concepts in mutualisms. Ecol. Lett. , 20, 577-590.

Shakeri, Y.N., White, K.S. \& Levi, T. (2018). Salmon-supported bears, seed dispersal, and extensive resource subsidies to granivores.Ecosphere, 9, e02297. 
Stamps, J. \& Groothuis, T.G.G. (2010). The development of animal personality: relevance, concepts and perspectives. Biol. Rev. , 85, 301-325.

Strauss, E.D. \& Holekamp, K.E. (2019). Social alliances improve rank and fitness in convention-based societies. Proc. Natl. Acad. Sci. , 116, 8919-8924.

Suraci, J.P., Smith, J.A., Clinchy, M., Zanette, L.Y. \& Wilmers, C.C. (2019). Humans, but not their dogs, displace pumas from their kills: An experimental approach. Sci. Rep. , 9, 1-8.

Tilson, R.L. \& Hamilton, W.J. (1984). Social dominance and feeding patterns of spotted hyaenas. Anim. Behav. , 32, 715-724.

Traveset, A. \& Richardson, D.M. (2014). Mutualistic interactions and biological invasions. Annu. Rev. Ecol. Evol. Syst. , 45, 89-113.

Tsuji, Y., Campos-Arceiz, A., Prasad, S., Kitamura, S. \& Mcconkey, K.R. (2020). Intraspecific differences in seed dispersal caused by differences in social rank and mediated by food availability. Sci. Rep., 10, 1532.

Vierling, K.T. (2000). Source and sink habitats of red-winged blackbirds in a rural / suburban landscape. Ecol. Appl. , 10, 1211-1218.

Wang, B.C. \& Smith, T.B. (2002). Closing the seed dispersal loop. Trends Ecol. Evol. , 17, 379-385.

Ward, A. \& Webster, M. (2016a). Distributions of costs and benefits within groups. In: Sociality: The Behaviour of Group-Living Animals. Springer International Publishing AG Switzerland, Gewerbestr. 11, Switzerland, pp. 111-124.

Ward, A. \& Webster, M. (2016b). Social foraging and predator-prey interactions. In: Sociality: The Behaviour of Group-Living Animals . Springer International Publishing AG Switzerland, Gewerbestr. 11, Switzerland, pp. $55-87$.

Ward, J.N., Hinton, J.W., Johannsen, K.L., Karlin, M.L., Miller, K. V. \& Chamberlain, M.J. (2018). Home range size, vegetation density, and season influences prey use by coyotes (Canis latrans ). PLoS One, 13, $1-22$.

Willson, M.F. (1993). Mammals as seed-dispersal mutualists in North America. Oikos , 67, 159-176.

Wittemyer, G., Getz, W.M., Vollrath, F. \& Douglas-Hamilton, I. (2007). Social dominance, seasonal movements, and spatial segregation in African elephants: A contribution to conservation behavior. Behav. Ecol. Sociobiol. , 61, 1919-1931.

Zimen, E. (1976). On the regulation of pack size in wolves. Z. Tierpsychol., 40, 300-341.

Zimen, E. (1981). The wolf, a species in danger . 1st edn. Delacorte Press.

Zwolak, R. (2018). How intraspecific variation in seed-dispersing animals matters for plants. Biol. Rev. , 93, 897-913.

Zwolak, R. \& Sih, A. (2020). Animal personalities and seed dispersal: A conceptual review. Funct. Ecol. , 34, 1294-1310.

\section{Tables and Figures}

Table 1. Example experimental designs to test our hypothesis using non-invasive methods that could be adopted for a wide variety of wildlife species, particularly for populations unhabituated to human observers. 


\begin{tabular}{|c|c|c|}
\hline Approach & Social status estimation & $\begin{array}{l}\text { Seed dispersal } \\
\text { measurements }\end{array}$ \\
\hline Experimental: Wild populations & $\begin{array}{l}\text { Social interactions: Remote } \\
\text { cameras to video-record behavior } \\
\text { of individuals in social context at } \\
\text { foraging stations Each station has } \\
2 \text { food items: primary resource } \\
\text { (e.g., carrion) and secondary } \\
\text { resource (fruit) Direction of } \\
\text { aggressive/submissive behaviors } \\
\text { indicates relative dominance } \\
\text { among individuals in a dyad or } \\
\text { group Food item selection by } \\
\text { solitary individuals confirms a } \\
\text { preference for primary resource } \\
\text { and role of social interactions in } \\
\text { frugivory Link individual behavior } \\
\text { to scat collection: Food items are } \\
\text { tagged with fine glitter or } \\
\text { fluorescent dye (unique color for } \\
\text { each station) Hair snags near each } \\
\text { food item to capture DNA } \\
\text { samples to ID individual } \\
\text { genotypes }\end{array}$ & $\begin{array}{l}\text { Dispersal distance: Presence/color } \\
\text { of glitter or dye in scat indicates } \\
\text { distance and direction of } \\
\text { movement from station Quantity } \\
\text { of seeds dispersed: Count number } \\
\text { of seeds per scat deposit } \\
\text { Germination trials to estimate \# } \\
\text { viable seeds per scat Sequence } \\
\text { DNA from scat to link individual } \\
\text { genotypes from scat and feeding } \\
\text { station assay Quality of seed } \\
\text { dispersal: Estimate rates of seed } \\
\text { removal (see Bartel \& Orrock } \\
2021 \text { for seed removal tray design) } \\
\text { in microhabitats where scat is } \\
\text { found }\end{array}$ \\
\hline $\begin{array}{l}\text { Experimental: Captive } \\
\text { populations }\end{array}$ & $\begin{array}{l}\text { Human observers record direction } \\
\text { of aggressive/submissive } \\
\text { behaviors to estimate each captive } \\
\text { group's dominance hierarchy Each } \\
\text { group is given } 2 \text { food items: } \\
\text { primary resource (e.g., carrion) } \\
\text { and secondary resource (fruiting } \\
\text { shrubs) }\end{array}$ & $\begin{array}{l}\text { Dispersal distance: Observations } \\
\text { of individual gut retention times } \\
\text { can be used with published } \\
\text { estimates of movement distances } \\
\text { in wild populations to estimate } \\
\text { potential dispersal distance } \\
\text { Quantity of seeds dispersed: } \\
\text { Count number of seeds per scat } \\
\text { deposit per individual } \\
\text { Germination trials to estimate } \\
\text { seed viability }\end{array}$ \\
\hline Observational: Remote sensing & $\begin{array}{l}\text { Remote cameras to video-record } \\
\text { behavior of individuals in social } \\
\text { context at primary resources } \\
\text { (e.g., carrion or fruiting trees) } \\
\text { and secondary resources (e.g., } \\
\text { fruiting shrubs) Direction of } \\
\text { aggressive/submissive behaviors } \\
\text { indicates relative dominance } \\
\text { among individuals in a dyad or } \\
\text { group Individuals may be } \\
\text { distinguished either visually in } \\
\text { photos or with radio-collars }\end{array}$ & $\begin{array}{l}\text { Dispersal distance: Published } \\
\text { estimates of gut retention times } \\
\text { and movement distances can be } \\
\text { used to estimate potential } \\
\text { dispersal distance Quantity of } \\
\text { seeds dispersed: Visually } \\
\text { estimated through video } \\
\text { recordings at fruit sources (\# of } \\
\text { visits and \# of seeds consumed } \\
\text { per visit) }\end{array}$ \\
\hline
\end{tabular}




\begin{tabular}{|c|c|c|}
\hline Approach & Social status estimation & $\begin{array}{l}\text { Seed dispersal } \\
\text { measurements }\end{array}$ \\
\hline $\begin{array}{l}\text { Observational: Molecular } \\
\text { analyses }\end{array}$ & $\begin{array}{l}\text { Extensive scat collection may } \\
\text { be done in systems where social } \\
\text { status carries a molecular } \\
\text { signature. Identify individuals } \\
\text { through genetic analysis of scat. } \\
\text { The following molecular } \\
\text { approaches may be used } \\
\text { estimate individual social } \\
\text { status: Fecal glucocorticoid } \\
\text { concentration is related to } \\
\text { dominance in some cooperative } \\
\text { breeding species (Creel 2001) } \\
\text { Reproductive hormone } \\
\text { concentrations may be used in } \\
\text { systems where reproductive } \\
\text { status affects dominance } \\
\text { Genetic analyses to identify sex } \\
\text { may be used when sex affects } \\
\text { dominance Average mass of scat } \\
\text { per individual may provide } \\
\text { estimation of individual size } \\
\text { when size affects dominance }\end{array}$ & $\begin{array}{l}\text { Quantity of seeds dispersed: } \\
\text { Count number of seeds per scat } \\
\text { deposit Germination trials to } \\
\text { estimate \# viable seeds per scat } \\
\text { Quality of seed dispersal: } \\
\text { Estimate rates of seed removal } \\
\text { in microhabitats where scat is } \\
\text { found }\end{array}$ \\
\hline
\end{tabular}




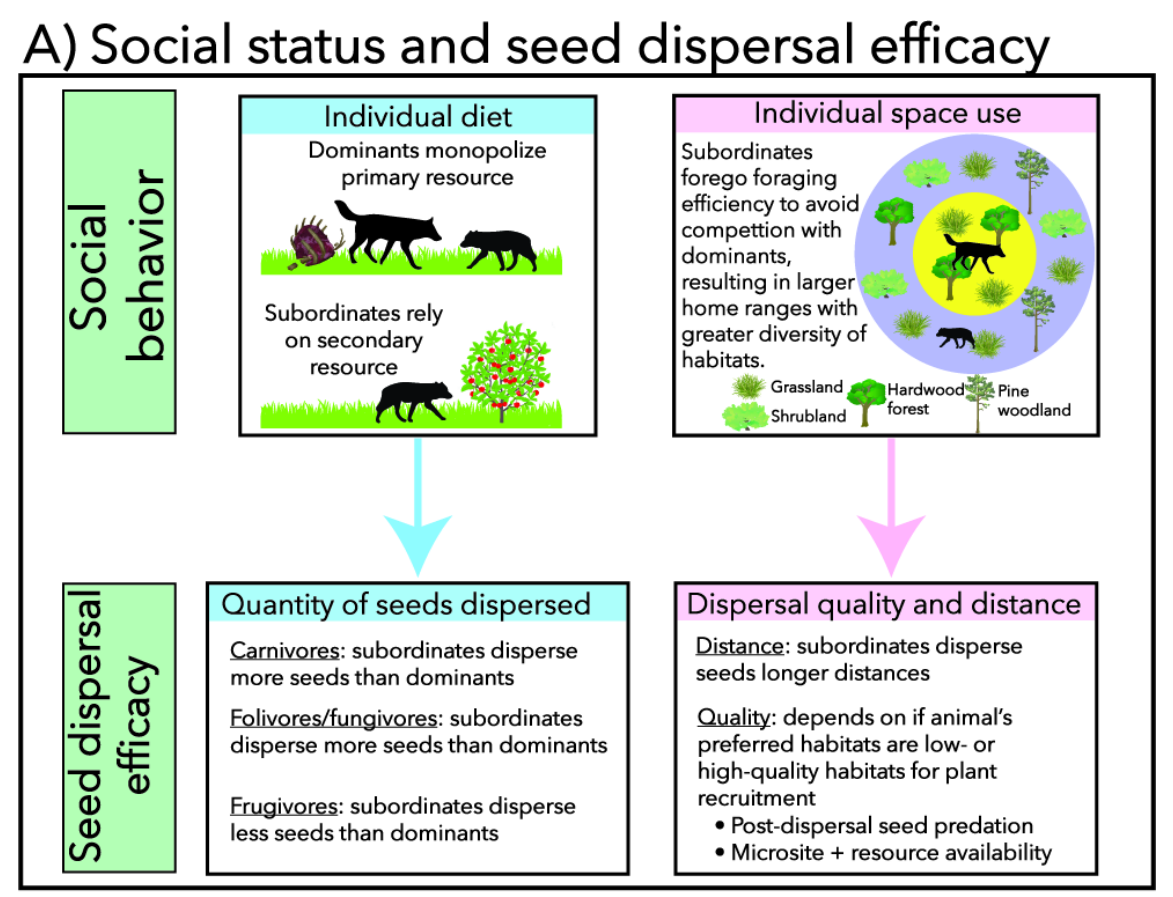

B) Predicted outcomes

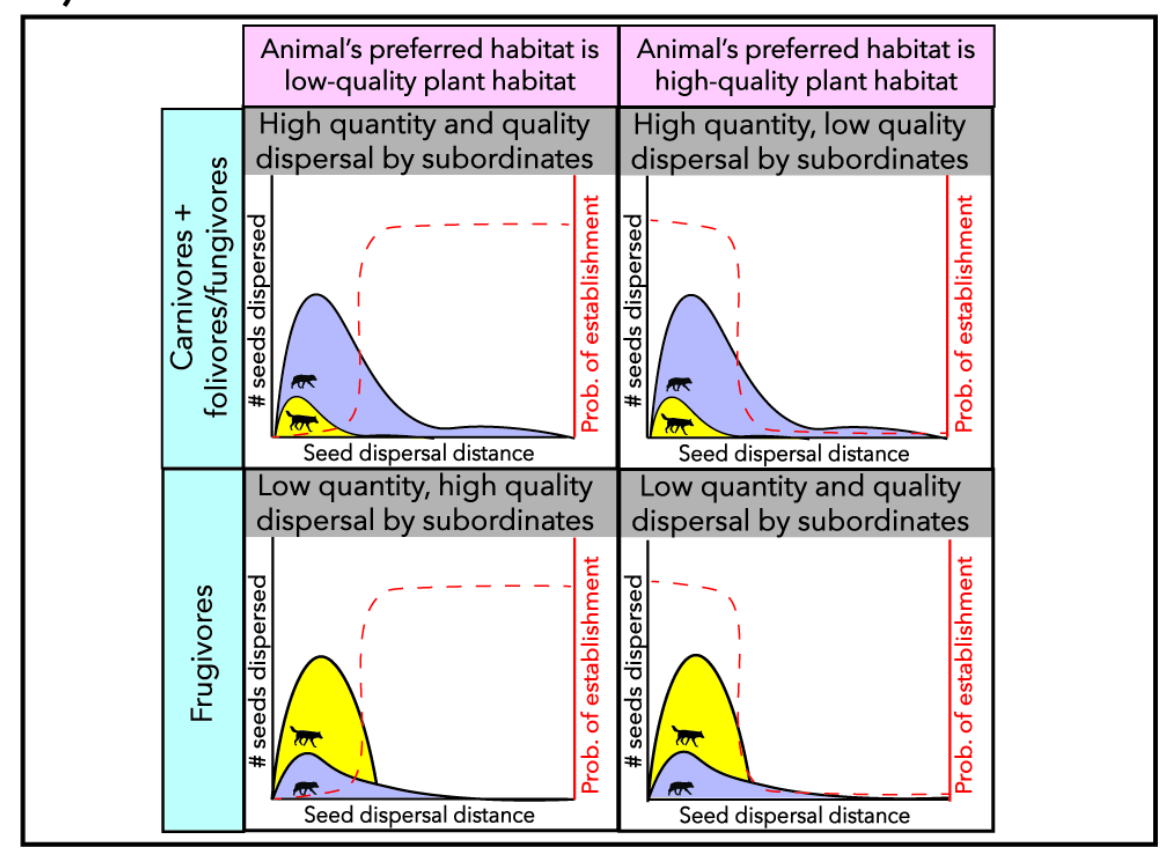

Figure 1. A) Social status has predictable effects on individual resource access and space use that may explain individual-level variation in seed dispersal effectiveness. Dominant individuals monopolize preferred resources, forcing subordinate individuals to supplement their diets to a greater extent with secondary resources. Subordinate individuals may then disperse disproportionately more or less seeds than dominant individuals, depending on whether fruit is the primary or secondary resource. While this hypothesis has been supported in recent work on Japanese macaques (Tsuji et al.2020), our framework demonstrates that this hypothesis could be applied to a broad range of taxa. Our framework is also novel in its demonstration of how 
social status may affect spatial patterns of seed dispersal, with clear consequences for seedling establishment. Dominant individuals typically defend territories with preferred habitat types, and subordinate individuals generally have less restricted home ranges, sample more habitat patches during a foray, and are more likely to go on extraterritorial forays. Subordinate individuals are consequently more likely to move seeds greater distances and deposit seeds in a broader diversity of habitat types. Since post-dispersal seed survival and plant recruitment are likely to vary across different habitats in a landscape (e.g., differences in granivore abundance or resource availability), the quality of seed dispersal services provided by subordinate individuals may differ substantially from dominant individuals. B) We provide predictions for the different types of seed dispersal kernels that may arise due to animal social behavior, highlighting that the outcome depends on food and habitat preferences of the animal dispersal agent.

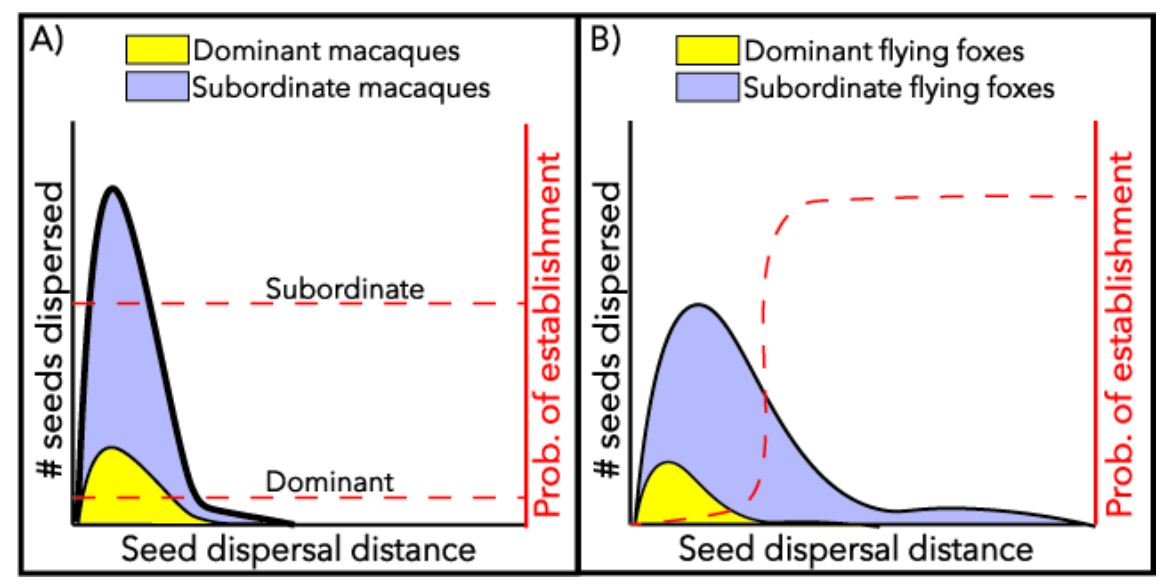

Fig 2. We provide predicted seed dispersal kernels and patterns of seedling establishment for the two case studies described in Box 2.A) Japanese macaques of different social statuses differ in seed-dispersal efficacy during non-masting years. Since subordinate macaques provide higher-quality dispersal (i.e., lower rates of seed mastication), we predict that the probability of seedling establishment will be greater for seeds dispersed by subordinates than those dispersed by dominant individuals, regardless of dispersal distance. B)Flying foxes of different social statuses differ in seed-dispersal efficacy. We expect that the probability of seedling establishment remains low when seeds are dispersed by dominant individuals because those seeds are dispersed directly below the mother tree. The probability of seedling establishment should increase when seeds are dispersed away from the mother tree by subordinate individuals, escaping intraspecific competition and natural enemies. 


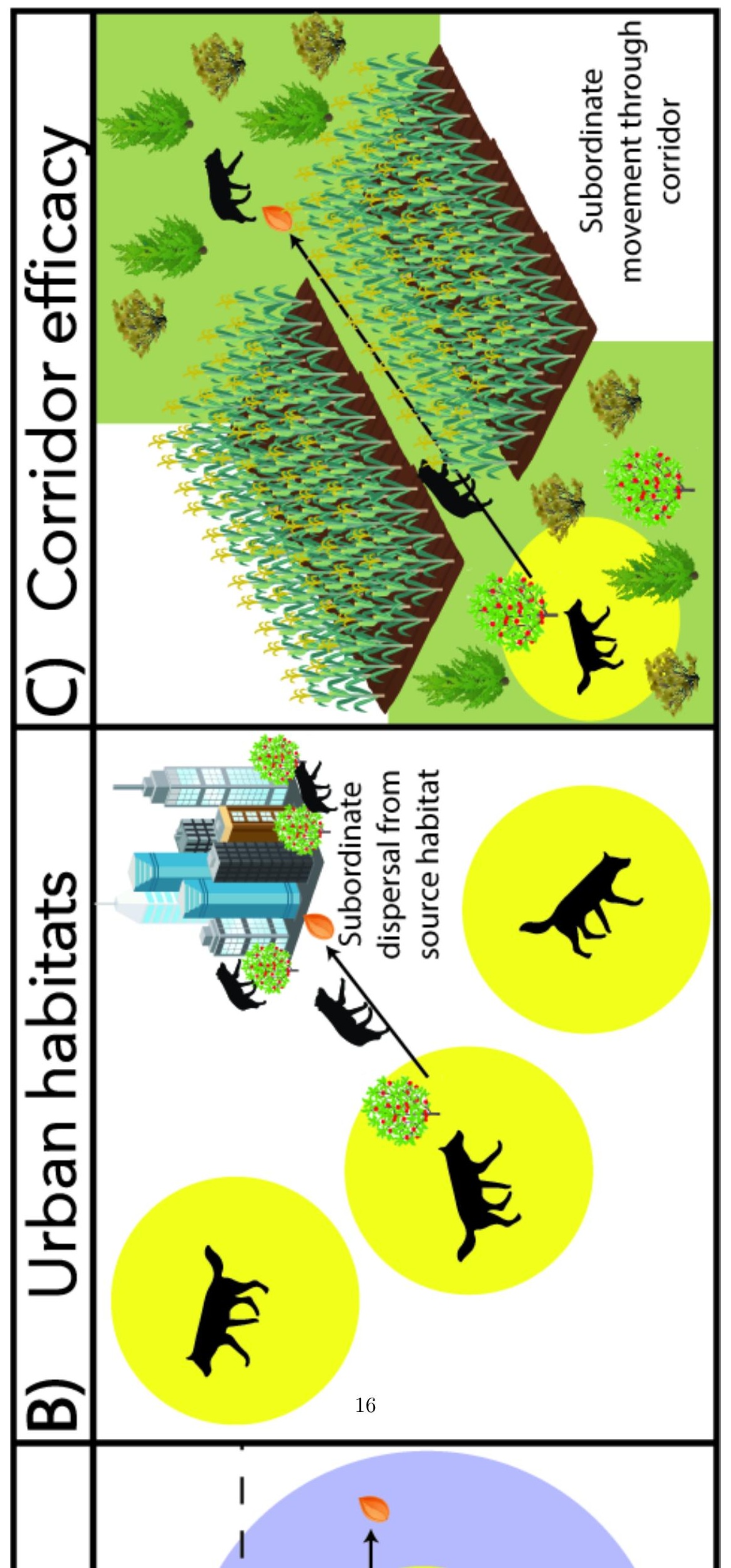


Figure 3. The effects of social status on seed dispersal may have important implications for the movement and recruitment of plants in the Anthropocene. A) Since subordinate individuals typically have larger home ranges and disperse beyond the territories of conspecifics, subordinate individuals are more likely to provide long-distance seed dispersal services. Since long-distance seed dispersal is critical for many plants to expand range boundaries, subordinate individuals may facilitate plant movement to track changing climate. B) Subordinate individuals are more likely to disperse into urban habitats. Subordinates may therefore facilitate plant species dispersal and persistence urban habitats. C) Since subordinate individuals have larger home ranges and are more likely to disperse beyond current conspecific territories, they may be more likely to use corridors. The movement of subordinate individuals through corridors likely facilitates plant movement through corridors, promoting plant establishment in otherwise isolated habitat patches.

\section{Boxes}

\section{Box 1. Carnivores as variable seed dispersal agents}

Carnivores can be important agents of directed, long-distance dispersal (Herrera 1989; Willson 1993; Rost et al. 2012; López-Bao et al. 2015; Hämäläinen et al. 2017; Shakeri et al. 2018), and rodent aversion to carnivore scat promotes the survival of scat-dispersed seeds (Bartel \& Orrock 2021). Individual niche specialization (i.e., where intraspecific variation in seed dispersal effectiveness should be most pervasive) is most common in upper trophic levels (Araújo et al. 2011), and many carnivore species exhibit high intraspecific variability in diet composition (Dumond et al.2001; Darimont et al. 2009; López-Bao \& González-Varo 2011; Cypher et al. 2014; Davis et al. 2015; Newsome et al. 2015; Manlick et al. 2019). For carnivore populations with dominance hierarchies, rank can constrain individual resource access (Zimen 1976, 1981; Tilson \& Hamilton 1984; Gese et al. 1996) and space use (Gese 2001; Henry et al. 2005; Dorning \& Harris 2017; Kamler et al. 2019), which likely produces predictable intraspecific variation in the quantity and distance of seeds dispersed. Below, we describe two carnivore species where recent work on social behavior indicates that social structure may predict individual seed dispersal effectiveness.

\section{Black-backed jackal (Canis mesomelas)}

Black-backed jackals have the potential to be effective seed-dispersal agents when soft mast, a supplementary resource, is included in individual diets (Do et al. 2009; Kamler et al. 2020). While it has not yet been evaluated whether individual rank within the dominance hierarchy affects soft mast consumption in this species, it has been shown that rank affects individual space use such that subordinate individuals move farther distances and are more likely to go on extraterritorial forays (Kamler et al. 2019), likely increasing the distance that seeds are moved and the diversity of habitats where seeds arrive.

\section{Brown bear (Ursus arctos)}

Brown bears consume the soft mast of at least 101 plant species spanning 24 families and 42 genera (GarcíaRodríguez et al. 2021). A single fecal deposit from a brown bear can contain thousands of seeds (Willson 1993), creating a massive seed dispersal event. While brown bears do not form cooperative packs, social dominance and subordination within populations has predictable effects on individual resource access and space use. In salmon-supported populations, dominant individuals (typically large males) displace subordinate individuals (particularly females with cubs) at salmon streams (Ben-David et al. 2004; Gende \& Quinn 2004). Since time spent at a salmon stream is positively correlated with salmon assimilation in brown bear diets and negatively correlated with plant matter assimilation (Deacy et al. 2018), it is likely that the monopolization of salmon streams by dominant individuals leads to consistently greater quantities of seed-dispersal services by subordinate individuals. Moreover, since the vast majority of long-distance movement by bears is done by dispersing subadults (Bartoń et al. 2019), these subordinate individuals are most likely to disperse plant species beyond current range boundaries (Fig. 3A). Lamb and colleagues (2020) also show that urban habitats serve as demographic sinks for brown bear populations, and urban populations are supported by immigration by dispersing subadults. These subordinate, subadult bears may therefore contribute substantially to the dispersal and persistence of some plant populations in urban areas (Fig. 3B). Since hunters typically target resident male bears (Gosselin et al. 2017; Leclerc et al. 2019), this form of selective harvest disrupts brown 
bear social structure, leading to increased infanticide when immigrant males disperse into newly opened territories (Gosselinet al. 2017). Whether or not the persistent disruption of brown bear social structure by selective harvesting generates cascading effects on seed dispersal remains an open question. Moreover, it is widely appreciated that brown bears use corridors to access otherwise isolated habitat patches, and corridors are particularly important for the dispersal of subadults into urban habitats (Clevenger \& Waltho 2005; Ford et al. 2017; Lamb et al. 2020). Corridors designed to facilitate brown bear movement through fragmented landscapes may therefore have unappreciated benefits for the dispersal of many bear-dispersed plant species.

\section{Box 2. Case studies where social status affects seed dispersal effectiveness}

Despite the pervasive effects of social status on individual resource access and space use, only a few case studies have demonstrated that the effects of social status on individual behavior lead to predictable patterns in intraspecific variation in seed dispersal effectiveness. Importantly, these case studies also illustrate that increases in availability of resources for subordinate individuals (e.g., masting events or population decline) can lead to seed dispersal limitation when subordinates no longer require fruit as a secondary resource or rely on thieving tactics. We provide predicted seed dispersal kernels and patterns of seedling establishment for both case studies (Fig. 2).

\section{Japanese macaques (Macaca fuscata)}

Japanese macaques are omnivorous primates that prefer nuts over soft mast. Tsuji et al. (2020) found that in a year when the preferred nut resource was low in abundance, high-ranking individuals monopolized this resource, forcing low-ranking individuals to consume and disperse soft mast. Low-ranking individuals also provided higher-quality seed dispersal as subordinates had lower rates of seed mastication (Fig. 2A). In contrast, during the masting year for nuts, there were no differences between social ranks in seed dispersal effectiveness. Since subordinate individuals had greater access to nuts, they consumed and dispersed less soft mast. Dominant individuals continued to be low-quantity seed dispersers, but the quality of seed dispersal increased during the mast year due to lower rates of seed mastication.

\section{Flying fox (Pteropus tonganus)}

Dominant flying foxes defend fruiting trees as territories, repelling subordinate intruders that seize fruit to consume in a distant location. Since dominant, territorial individuals rarely move away from the trees they defend, most seeds dispersed by these individuals fall below the mother tree. Since subordinate individuals move seeds further distances from the mother tree, these individuals provide higher-quality and long-distance seed dispersal (Fig. 2B). However, in order for subordinate individuals to exhibit this fruit-thieving strategy, all fruiting trees need to be saturated with dominant, fruit-defending individuals. McConkey et al. (2006) show that once flying fox densities fell below a certain threshold, trees were no longer saturated by dominant individuals, allowing most individuals to remain in their trees, reducing the frequency of fruit-thieving behaviors and rates of seed dispersal away from defended trees. 